\title{
The Search for an Educational Paradigm in the Information Reality
}

\author{
Daniil Kvon ${ }^{1, *}$ Tatiana Pavlova ${ }^{1}$ \\ ${ }^{1}$ Department of Philosophy, Moscow Aviation Institute, Institute of Engineering Economics and Humanities, \\ Moscow, Russia \\ *Corresponding author. Email: vptp52@mail.ru
}

\begin{abstract}
The researchers examine the urge for a new educational paradigm at times of the fourth industrial revolution, analyze the functions and features of the new digital educational environment. The new education standards implement the transition from fixed qualifications and specialties to flexible specializations focused on the needs of the labor market. The educational process is specified in its following manifestations: learning as a process of cognitive activity; education as a socialization process. The new paradigm of education requires the molding of a specialist's broad intellect, which creates motivation for professional activity in the context of the existing information culture. The authors of the article propose a strategy for shaping a new digital educational paradigm based on the principles of consistency, diversification, the integrity of the educational environment, continuity of education, individualization, and cultural studies content.
\end{abstract}

Keywords: Digitalization, Educational paradigm, Information technology, Diversification, Artificial intelligence, Distance learning, Process.

\section{INTRODUCTION}

Philosophical and methodological aspect of the analysis of the primary functions of education is associated not only with the need to create a new paradigm of education but with a shift in thinking, the angle of view on the processes and prospects of the modern educational process.

The development of theoretical knowledge allows their application in various fields of social interaction. Modernization of the educational environment is impossible without the introduction of the latest information technology solutions.

Humanity is gradually being digitized. People themselves are undergoing revolutionary changes. Chris Skinner, a notable expert in digital technology, defined the person who will live in the $21^{\text {st }}$ century as a digital human. In his eponymous book Digital Human, he attaches great importance to forming a new educational environment of society, where the future personality will be formed [1].

The analysis of academic sources on education shows that the elaboration and theoretical comprehension of the educational environment concept intensified in the late $20^{\text {th }}$ century. Despite the different approaches to its study, researchers single out as an essential educational environment's distinguishing feature the fact that it is an integral part of the socio-cultural background as a set of historically established factors, circumstances, influences, and ideas. Thus, it is the integrity of specially organized educational conditions, aiming at the formation and development of the student personality.

The relevance of the topic of the presented study links primarily to the fact that the new digital learning environment turns into the platform, requiring changes in the model and forms of learning. As an open system, the digital learning environment provides any user with the opportunity and the right to use various information systems to solve various problems. 


\section{THE ROLE OF INFORMATION TECHNOLOGY IN THE EDUCATIONAL ENVIRONMENT OF THE LATE $20^{\mathrm{TH}}-$ EARLY $21^{\mathrm{ST}}$ CENTURY}

Compared to an industrial society, where everything is directed to the manufacturing and consumption of goods, the information society produces and uses intellect, knowledge, which leads to an increase in the share of mental labor. This paradigm shift required new structural transformations of the educational environment, transforming it into an open system.

The introduction of the principle of diversification in the organization of the education system allows diversity, versatility, and variability in the development of educational institutions and their management bodies. One of the key features characterizing the receipt of tuition in various forms becomes the continuity of learning.

In his writings, British sociologist John Urry argues that the emergence of a new paradigm to replace the existing one is a non-linear and unpredictable process. Any new system is related to the previous one because in the old paradigm, innovative ideas of practice had already matured. In this case, synthesis of old and new means combining individual elements in a new order [2].

The conclusion is as follows. If the new educational environment enters as an element of the integral social system along with the economic, political, technological dimensions, then the innovation processes take a long time. Consequently, in the new system, the interconnections between its elements must be established, subsequently creating a certain field around itself and a vector that organizes people into specific activities.

The President of the World Economic Forum in Davos, Klaus Schwab, in his book, The Fourth Industrial Revolution, tried to set a conceptual framework for understanding the technological revolution, noting its global nature and the rapid pace of development. An individual will not experience human vs. machine competition because the rise in productivity in the new paradigm will increase not at the expense of an increase in new means of production but the expense of the need for a quality creative worker.

Schwab, in his conclusion, relies on the opinion of representatives of the economic sector. They argue that in digital reality when hiring, an employer will consider the contextual intelligence of a candidate. That is defined as the ability and willingness to anticipate emerging innovations, where the feature of this intelligence is integrity, flexibility, and adaptability to constantly integrating diverse interests and opinions [3].

There has long been a debate in higher education on how to shape the intellectual abilities of future professionals. Higher education aims to form the intellectual abilities of the personality, its spiritual identification, and motivation. The intellect's quality is determined by the extent to which an individual can be included in the meanings of existence and how much they put them into action. Here it is appropriate to pay attention to the problems of research of correlation of psyche, brain, and education, which are considered in the article of the Russian philosopher Knyazeva H.N. Nonlinear Cobweb of Cognition. Developing the concept of enactivated cognition, she concluded that through learning, "The same nonlinear connections of co-determination are established by the writing of a text of composition in the process of a verbal (especially literary) creative work" [4].

The next direction that information technology brings to the educational process is developing models of cooperation between universities and businesses. The idea of university-business cooperation was forged in the late 1980s in the USA due to the declining quality of engineering training in higher education. This prompted the largest US corporations to subsidize the modernization of research equipment in universities and cover the costs associated with the professional development of young specialists.

Thus, for the first time, a new concept of the "commercialization process" was introduced into the educational environment. Such structures as the States' Silicon Valley, innovation centers in Karlsruhe in Germany, the being created Skolkovo innovation center in Moscow, communicate the positive energy of forming new connections around universities, both in form and content. 
The issues of embedding information technology in the educational environment are primarily due to universities' outdated material and technical base. This challenge requires getting involved in commercialization, where a business would be interested in interconnecting with a university. The companies themselves are not able to look for scientists whose research could become the foundation for new market products. This would require the establishment of new structural organizations that could lay the groundwork for problem-oriented research. However, it is not easy to find organizing bodies willing to cooperate with one or the other side. The composition of these new structural organizations must include creative thinkers with contextual intelligence since their task is to explore the needs of businesses for research results. On the other hand, businesspeople point out negative phenomena in universities' educational process, such as the refusal to change the creation of new curricula aimed at the use of methods of systems analysis, systems engineering, etc. The digital educational environment and its quality will depend on the education-research-practice cluster, where a big role is played by practical training at the university and internships at industrial enterprises.

Various approaches and methods in businessuniversities cooperation are presented in the academic environment. Various forms were investigated through a survey conducted in EMCOSU countries (Emerging Modes of Cooperation between Private Sector and Universities), with Russia's participation, summarized by A.L. Kekkonen and S.V. Sigova. Based on the results of this research, the most distinctive forms of interaction between universities and business are:

- Interaction through the educational process (participation of representatives of information companies as guest lecturers).

- Interaction through the educational process, participation in the development and accreditation of the necessary educational programs on information technology.

- Interaction through research, when companies provide funding for developing innovative information technologies by university staff, signing contracts with professors and students.
- Interaction through extracurricular activities, participation in joint conferences, university open days, and field seminars at enterprises related to IT development [5].

\section{THE IMPACT OF ARTIFICIAL INTELLIGENCE ON THE EDUCATIONAL PROCESS}

Our century witnesses the formation of a computer virtual environment, determined by both the presence of humans in the computer network and the computer network in the lifeworld of human existence. The analysis on the promotion and use of information technologies in education, which was published by the UNESCO Institute for Information Technologies in Education, in a 2020 policy brief by Steven Duggan AI in Education: Change at the Speed of Learning, is of interest in the practical work of the educational process. Duggan notes that the effective implication of artificial intelligence, data, analytics, and machine learning can allow educators to make learning more engaging by using technology to immerse them in a virtual environment.

New technologies increase the significance of the teacher's role since they empower pedagogues but cannot simply replace them. In an educational context, AI is best viewed as an additional amplified intelligence. Its use allows all sides of learning to obtain additional information and draw the conclusions needed to make more informed decisions [6].

The methodology of artificial intelligence research consists of developing a variety of theories, techniques, and technologies. Its main directions are the following:

- Machine learning method development is a field of knowledge that explores algorithms trained on data to find patterns. It uses neural networks, statistics, operations research, etc., to identify useful hidden information. Shumsky S.A., a professor at Moscow Institute of Physics and Technology, Ph.D. in Physics and Mathematics, in his work Machine Intelligence. Essays on the Theory of Machine Learning and Artificial Intelligence proposed several methods for the basics of machine learning. Common applications are image and speech recognition [7]. 
- Natural language processing is the ability of computers to analyze, understand, and synthesize human language, including spoken one. We can already control computers with our ordinary everyday language. This will allow a faster transition to scientific research since AI makes it possible to memorize and process vast amounts of data. Nevertheless, the difficulty of this development is associated with a lack of resources: computer and human resources, as science-intensive development of intelligent software, requires the involvement of leading experts in different fields of knowledge and organization of long-term research projects. This problem is raised by T. Davenport in his The AI Advantage: How to Put the Artificial Intelligence Revolution to Work [8].

- The study of the new high-tech culture analyzes the changing pivotal values of the entire world civilization. The digitalization of all human life is a global anthropological challenge.

As we can see, artificial intelligence can be understood as a scientific direction and various devices capable of reflection, simulating human intelligence. Speaking about the change of educational programs, it is necessary to contemplate the inclusion of artificial intelligence problems in various disciplines, both technical and humanities.

As Russian neuroscientist T.V. Chernigovskaya notes, the development of cognitive research has serious fundamental importance and practical benefit for applied fields, primarily medicine, pedagogy, psychology, and education. She emphasizes the dependence of research on the upbringing and training of cognitive scientists in the educational system. Her research is an example of the convergent and transdisciplinary development of science. The significance of such work is underscored in her book, which presents an analysis of the author's research series, Cheshire Smile of Schrödinger's Cat: Language and Mind. "The anthropological worldview role of this field of knowledge is indisputable: we want to understand who we are... It is also quite clear that such a complex field requires not only the cooperation of scientists of different profiles, but specialists of another, multidisciplinary type, and they should be trained in the best universities" [9].

\section{DISTANT LEARNING TECHNOLOGY}

The problems of distance learning and its applicability are considered from two sides: the provision of material and technical base of universities and the position of the formation of specific methods and approaches to implement a distance learning format. The conducted research notes that there is a digital divide among teachers, students, and university management. Digital divide, or information gap, is a new concept that steadily entered the modern vocabulary meaning the gap between those who have access to information technology training and those who have no such opportunity. Distance learning technology is many educational techniques implemented using modern information and telecommunication technologies in the application of which the interaction between a teacher and a student is carried out indirectly, distantly.

In the difficult period of quarantine isolation, the universities were assigned the following tasks, the implementation of which should maintain the efficiency and quality of the educational process:

\subsection{High Coverage of the Audience of Students}

With the appropriate material, technical, educational, and organizational base, one teacher can cover a much larger audience of students and monitor the quality of their knowledge than in the traditional educational process. When applying a distance learning format, it is possible to teach students regardless of their geographical location.

\subsection{Ensuring the Efficiency and Quality of the Educational Process}

Providing the learning process in humanities education is different from that associated with human productive activities. In learning philosophy using information technology, we aimed to identify each student's abilities and adapt the pace and content of the learning process to them.

The primary task is not to broadcast specific knowledge to the student but to try and direct their 
thinking to find original solutions to problems. The e-learning course includes multimedia lectures, webinars, online seminars, interactive manuals, tutorials, and methodological materials. Online lectures, practical classes held in the form of a webinar allow the student to ask questions and get an answer right before the end of the webinar or give his version of the solution to the problem in written form, making it public on the forum of the discipline, a discussion which can cause a discussion not only with the professor but also with other students. Electronic textbook navigation based on hypertext and multimedia capabilities is a more convenient and visually flexible tool than a traditional paper textbook.

\subsection{Formation of Students' Information Culture as a Necessary Cultural Principle of Distance Learning}

There is a change in the educational environment of learning, where the central place belongs not so much to a professor as an information carrier but to the visual image, which is based on the screen-computer image flow, including a variety of text, graphic, and sound information. When transmitting information, the computer becomes an intermediary between the learner and the real world around him.

In distance learning, a humanities professor must master sophisticated usage of information sources, primarily to distinguish different meanings in their analysis.

First, the Internet gives students great freedom in constructing their version of events. However, there is a very real danger of a superficial, semantically insufficient description of the history, political evaluation, moral situations, the possibility of a somewhat crazy construction of different points of view in virtual space.

Secondly, a serious problem is the reliability of electronic information. In this situation, we may agree with L.E. Motorina and G.V. Chernyaeva that there is an objective basis for the statement that the functions of virtual psychological reality actualize and differentiate as problems arise not only in obtaining knowledge but also in everyday life of an individual. Under certain conditions, it can dominate over authentic reality, as if absorbing it. The new subjective vision created by virtual reality is more likely to be perceived as a simulacrum as the correct point of view [10].

Thus, when developing a distance learning methodology, a professor must rely on such principles as consistency, integrity, differentiation, individualization. The realities of today become the requirements of high professionalism [11].

In the distant learning process, the following features are positive:

- The ability to solve complex problems, store large amounts of information and work with them.

- The ability to supplement existing knowledge, relative independence in assessing the situation, and critical evaluation of incoming information material.

- The ability to deductive inference, i.e., generation of information that is not explicitly contained in the system.

- The ability to interact in dialogue with a person who speaks another language.

On the other hand, there is a limitation to the full implementation of technology in the educational environment:

- The inertia of the educational system and the potentially long process of mastering the methodology of artificial intelligence technologies by teachers.

- A number of technological limitations hinder the development and implementation of the system, as it is necessary not only to digitize the sources but also to create a system to verify the meta-information, context, and content.

\section{CONCLUSION}

Summarizing the results of the study, the following conclusions are made:

- The existence of the dynamics of new educational concepts confirms that the phenomenon of education is innovative.

- The system analysis revealed trends in changing the methodology of the educational process in connection with the creation of new forms in educational, research, and other intellectual activities 
and connection with the transition to new information technology training.

- The study identified opportunities for the teacher and the student in connection with the introduction of distance learning. The authors believe that new methodological developments are needed, which will help to form a culture of working in information networks, both the teacher and the student.

A strategy for forming a new digital educational paradigm based on the principles of consistency, diversification, the integrity of the educational environment, individualization, and cultural content is proposed.

\section{AUTHORS' CONTRIBUTIONS}

Daniil Kvon researched opportunities of teachers and students in connection with implementation of distant learning, as well as relations between higher school and business in the area of specialists' preparation

Tatiana Pavlova analyzed influence of the artificial intelligence upon education process and proposed a strategy of shaping a new digital educational paradigm.

\section{REFERENCES}

[1] Skinner Chris. Digital Human: The Fourth Revolution of Humanity Includes Everyone / Chris Skinner: translated from English by O. Sivchenko; [ed. by K. Sheglova]. - M.: Mann, Ivanov \& Ferber, 2019, - 304 p.: illustrated.

[2] Urry John. What Is the Future? / John Urry; translated from English by A. Matveenko; under the scientific ed. S. Schukina. - M.: Publishing house "Delo" RANEPA, 2019. $2019 \mathrm{~b}-320 \mathrm{p}$.

[3] Schwab Klaus. The Fourth Industrial Revolution: [translated from English] / Klaus Schwab. - Moscow: Eksmo, 2019. - 218 p.

[4] Knyazeva H.N. Nonlinear Cobweb of Cognition // Man No. 2, 2006. - C. 21-33.

[5] Kekkonen A.L., Sigova S.V. Development of Cooperation Models of Higher Education and Business: European and Russian Experience// Innovations, №3 (209), 2016. - P 82-87.
[6] AI in Education: Change at the Speed of Learning. Analytical note by UNESCO IITE / Stephen Duggan; ed. by S.Yu. Knyazeva; translated from English: A.V. Parshakova. Moscow: UNESCO Institute for Information Technologies in Education.

[7] Shumsky S.A. Machine Intelligence. Essays on the Theory of Machine Learning and Artificial Intelligence. - M.: RIOR INFRA-M, 2020, - 340 p.

[8] Davenport Thomas. The AI Advantage: How to Put the Artificial Intelligence Revolution to Work/Thomas Davenport, translated from English: Alpina Publisher, 2021, - 316 p.

[9] Chernigovskaya T.V. Cheshire Smile of Schrödinger's Cat: Language and Mind. Moscow: YASK Publishing House: Languages of Slavic Culture, 2017. 3rd ed. $448 \mathrm{p}$.

[10] Motorina L.E., Chernyaeva G.V. Psychological virtual reality in a computer interactive environment // Social Psychology and Society, 2020, Volume 11, №1. P. 8-26.

[11] Tsvyk I.V. Professional Consciousness of Personality: Concept and Structure//Journal of Peoples' Friendship University of Russia (RUDN University). Philosophy Series №1 (10-11), 2004-2005. P. 104-116. 